\title{
Behavioral functioning of school-aged children with non-syndromic craniosynostosis
}

\author{
Senem Zeytinoğlu-Saydam ${ }^{1}$ (D) M. Memet Özek ${ }^{2} \cdot$ Justin Marcus $^{3} \cdot$ Canice Crerand $^{4}$
}

Received: 23 February 2019 / Accepted: 8 November 2019 / Published online: 10 December 2019

(C) Springer-Verlag GmbH Germany, part of Springer Nature 2019

\begin{abstract}
Purpose This study investigated the risk for children with non-syndromic craniosynostosis to develop behavioral problems during school age determined by the type of craniosynostisis, age at first surgery, and number of surgeries.

Method Final sample consisted of 43 children aged between 6 years and 8 months and 17 years and 1 month $(M=10$ years and 5 months). Behavioral problems were assessed with Child Behavioral Checklist (CBCL).

Results Our sample had higher scores on the CBCL than the general population; specific elevations were observed including somatic complaints, aggressive behavior, social problems, attention problems, and thought problems and rule-breaking behavior. Behavioral functioning varied by number of surgical procedures, type of craniosynostosis, and age at first surgery.

Conclusion For school-aged NSC children's behavioral functioning, diagnosis specific patterns especially impacted by the first age of the surgery and number of surgeries.
\end{abstract}

Keywords Trigonocephaly $\cdot$ Scaphocephaly $\cdot$ Plagiocephaly $\cdot$ Psychology

\section{Introduction}

Craniosynostosis is a craniofacial disorder characterized by an early fusion of one or more cranial sutures. It usually has a prenatal onset, occurring 1 in 1700 to 2500 births [1]. Craniosynostosis can also be accompanied by more than 130

Senem Zeytinoğlu-Saydam

senem.zeytinoglu@ozyegin.edu.tr

Justin Marcus

jmarcus@ku.edu.tr

1 Department of Psychology, Özyeğin University, Çekmeköy Kampüsü Nişantepe Mahallesi Orman Sokak Çekmeköy, 34794 İstanbul, Turkey

2 Department of Neurosurgery, Division of Pediatric Neurosurgery, Acıbadem University, Altunizade Mahallesi, Yurtcan Sokağı No:1, Üsküdar, 34662 İstanbul, Turkey

3 College of Administrative Sciences and Economics, Koç University, Rumelifeneri Mahallesi, Rumelifeneri Yolu, Sarıer, 34450 Istanbul, Turkey

4 Department of Pediatrics, The Ohio State University College of Medicine, and Center for Biobehavioral Health, The Abigail Wexner Research Institute at Nationwide Children's Hospital, 700 Children's Drive, Columbus, OH 43205, USA syndromes, although most cases are non-syndromic. Nonsyndromic craniosynostosis (NSC) can be classified by the number and location of the fused sutures as scaphocephaly, trigonocephaly, and plagiocephaly $[1,2]$.

Treatment for craniosynostosis typically entails reconstructive surgery to reshape the skull and release the fused sutures. Surgery is primarily for concerns about intracranial pressure, neurodevelopmental delays, and improved esthetics [1,3-5]. Although minimal, a positive impact of early surgery in neurological, motor, and speech development has been demonstrated through research [3, 4, 6-8]. Early repair is also recommended for technical advantages: fast recovery, risk for fewer complications, re-synostosis, minimal scarring, and psychological advantages such as lower risk of experiencing bullying in school due to "abnormal" head shape [5,9]. Yet, some research studies indicate that risk of behavioral and emotional problems, learning disabilities, and lower neurological functioning does not disappear with early surgery, proposing that craniosynostosis involves structural brain malformations leading regardless of surgical treatment $[10$, 11].

Multiple research studies demonstrate a risk in children with NSC, specifically for school-aged children. Researchers consistently reported minimally elevated scores in Child Behavioral Checklist subscales of social problems, attention problems, internalizing and externalizing problems, and total scores, but these 
differences are small and may not be clinically meaningful [12-14].

Most studies of children with craniosynostosis have mainly focused on investigating cognitive and motor development and the impact of the timing of the surgery and the type of the craniosynostosis on these aspects $[1,8$, 15]. There has been some evidence supporting that behavioral functioning and neurodevelopment of the affected children differ based on the type of craniosynostosis, with problems with neurological and behavioral functioning being the least prevalent in sagittal craniosynostosis than in metopic, unicoronal, and lambdoid craniosynostosis [8, 14, 16, 17]. Even though not specific to craniosynostosis, some research studies allude to the long-term behavioral and emotional impact of going through surgeries, particularly repeated surgeries in children [18]. For this reason, it is possible that long-term behavioral functioning of the children would be impacted by the age of the first surgery, number of surgeries, and type of the craniosynostosis. Thus, this study aimed to investigate the following:

(1) Are school-age children with NSC at clinical risk for behavioral problems?

(2) Does children's behavioral functioning differ based on the suture location, age at first surgery and number of surgeries?

\section{Methods}

\section{Participants and procedures}

The second author's patient database was reviewed for participants that met the inclusion criteria between the years of 1998 and 2010 (Turkish as their native language, aged between 6 and 18, in school, diagnosed with nonsyndromic NSC, had received surgery, and routinely followed up since).

The search yielded 118 children. Upon receiving approval from the Institutional Review Boards (Protocol no: 2015-10/ 7), parents of the children were contacted, introduced to the study, and informed consent was obtained. Parents who agreed to participate received questionnaires via email. Chart reviews were conducted to verify medical history data reported by parents.

In all, 51 parents (43.2\% of 118) sent back the surveys via email. Eight surveys were excluded: three due to the synostosis type not being reported, four due to the presence of an accompanying syndrome not reported in the child's file, and one with missing information on age of first surgery and number of operations. The final sample $(N=43)$ included 31 boys and 12 girls.

\section{Measures}

\section{Demographic form}

Parents answered questions child's date of birth, child's gender, type of child's craniosynostosis, additional medical diagnoses child's age at the time of the diagnosis, and the surgery and number of surgeries the child received for both craniosynostosis and other reasons as well. Information provided was confirmed with chart review.

\section{Child behavior checklist}

The CBCL [19] is a parent report instrument to assess emotional, social, and behavioral problems in children between ages 6 and 18 years. Higher scores indicate greater problems. The scale has been translated and validated for use in the Turkish population [20, 21] with norms available for both general and clinical populations. The norm group of the general population includes 4278 Turkish children aged between 6 and 18 whereas the norm group of the clinical population includes 963 . The CBCL also includes questions about the child's school success and social activities. The psychological functioning component has 113 items and 8 subscales: anxious/depressed, withdrawn/depressed, somatic complaints, social problems, thought problems, attention problems, rule breaking behavior, and aggressive behavior. Respondents rated their responses in a Likert scale form from 0 to 2 ( $0=$ "not true", 2 = "usually true"). Based on the findings of Turkish reliability and validity analyses, all subscales had acceptable test re-test and internal reliability. Scale test-retest reliability ranged between 0.76 and 0.90 [20, 22]. The instrument also contains subscales assessing Diagnostic Statistical Manual (DSM) diagnoses, including depressive problems, anxiety problems, somatic problems, attention and hyperactivity disorder, oppositional defiant problems, conduct problems, processing speed, obsessive compulsive disorder, and post-traumatic stress disorder (PTSD). Scale test-retest reliability ranged between 0.80 and 0.91. The Cronbach alphas of the subscales for this study are presented in Table 3. Due to low Cronbach alphas in our sample, the slow cognitive tempo and rule breaking behavior subscales were not included in further analysis.

\section{Analytical procedures}

\section{Data preparation}

Less than $5 \%$ of data were missing on any of the dependent variables. Accordingly, in line with suggested best practices, missing data were imputed using maximum likelihood 
estimation [23]. Based on recommended survey data preparation procedures [22], multivariate outliers were discarded prior to analyses involving multiple factors, resulting in one discarded outlier per analysis. Data were analyzed using SPSS GLM, with existence of additional diagnoses, age of first diagnosis, and parents' education level included as covariates, and age of first surgery, number of surgical operations, and craniosynostosis type as independent variables.

\section{Normed comparisons}

To answer the first research question, the current sample was compared to both the general and the clinical population on the CBCL variables, via reference to the normed scores as available via Erol and Simsek [21]. For each normed comparison, a one-sample $t$ test was conducted.

\section{Multivariate analyses (GLM)}

To address the second research question, rule breaking behavior and aggressive behavior were analyzed together as externalizing problems, using SPSS GLM Multivariate; similarly, anxious/depressed, withdrawn/depressed, and somatic complaints were analyzed together as internalizing problems, using SPSS GLM Multivariate. Thought problems, social problems, and attention problems were each analyzed separately using SPSS GLM Univariate.

For analyses related to the DSM-oriented scales, oppositional defiant problems and conduct problem behavior were analyzed together as externalizing disorders, using SPSS GLM Multivariate; similarly, anxiety problems, depressive problems, and somatic problems were analyzed together as internalizing disorders, using SPSS GLM Multivariate. Attention deficit-hyperactivity disorder (ADHD), obsessivecompulsive disorder (OCD), and posttraumatic stress disorder (PTSD) were each analyzed separately using SPSS GLM Univariate. In all, a total of five analyses (two multivariate and three univariate) were conducted for CBCL-dependent variables, and three analyses (two multivariate and three univariate) were conducted for DSM-dependent variables.

\section{Alpha level considerations}

The alpha level for tests of statistical significance was set to the conventional $\alpha=.05$ level of significance for main effects and two-way interactions. However, because higher-level (e.g., three-way) interaction effects suffer from low statistical power, and in line with suggested best practices for tests of such higher-order effects [24], $\alpha=.10$ was used as the appropriate level of significance for hypothesis tests involving three-way interactions, and particularly given the limited sample sizes involved. Statistically significant interactions were graphed using the "Interactions software" by Sloper [25].
For reporting brevity, only statistically significant results are reported below.

\section{Results}

\section{Demographic characteristics}

At the time of data collection, children's ages ranged between 6 years and 8 months and 17 years and 1 month $(M=10$ years and 5 months). The age at first surgery ranged between 2 and 42 months, mean was 9.65 months ( $S D=9.72$ months). Age at time of the diagnosis ranged between 0 and 36 months with a mean of 6.78 months ( $S D=8.24$ months). The number of surgeries ranged between one and four $(M=1.40)$. Reasons for surgeries involved major remodeling, closure of simple bone defect, removal of metallic plates, and screws and esthetic correction of incision scars. There were 18 children diagnosed with scaphocephaly, 16 with trigonocephaly, and 9 with plagiocepahly. Three children had additional diagnoses, which are attention deficiency, near sightedness, and speech dysfunction. Parents' highest level of education received was doctorate. More than half of the parents (\% 66.7) had completed college or graduate school.

\section{Normed comparisons}

\section{CBCL comparisons}

Normed comparisons on the CBCL for the current sample viaa-vis both as the societal and clinical samples are summarized in Table 1. As shown in Table 1, the current sample exhibited significantly more somatic complaints, aggressive behavior, social problems, thought problems, and attention problems than the societal sample; in no case was the current sample less likely to exhibit problematic behaviors than the general population norms. Conversely, and as shown in Table 1, the current sample exhibited significantly less anxiety, social isolation, disobedience, problems with thoughts, and social problems than the clinical sample; in no case was the current sample more likely to exhibit problematic behaviors than the clinical sample.

\section{DSM comparisons}

Normed comparisons on the DSM for the current sample relative to the clinical population are summarized in Table 2. As shown in Table 2, the current sample was significantly lower than the clinical population on most DSM variables and was never found to be significantly higher than the clinical population on any variable (Table 3 ). 
Table 1 Normed comparisons to normal and clinical populations on CBCL variables

\begin{tabular}{lllll}
\hline Variable & Sample descriptives & Comparison group values & $\begin{array}{l}\text { One-sample } t \text { test results } \\
\text { (societal group) }\end{array}$ & $\begin{array}{l}\text { One-sample } t \text { test results } \\
\text { (clinical group) }\end{array}$ \\
\hline Anxious & $M=4.43 ;$ & Societal group: $\mu=4.3$ & $t_{(50)}=.288 ;$ & $t_{(50)}=-7.688 ;$ \\
& $S D=3.22$ & Clinical group: $\mu=7.9$ & $p=.77$ & $p<.001$ \\
Withdrawn & $M=2.42 ;$ & Societal group: $\mu=2.2$ & $t_{(50)}=.625 ;$ & $t_{(50)}=-4.623 ;$ \\
& $S D=2.45$ & Clinical group: $\mu=4.0$ & $p=.54$ & $p<.001$ \\
Somatic complaints & $M=2.67 ;$ & Societal group: $\mu=1.3$ & $t_{(50)}=2.826 ;$ & $t_{(50)}=.349 ;$ \\
Aggressive behaviors & $S D=3.46$ & Clinical group: $\mu=2.5$ & $p<.01$ & $p=.73$ \\
& $M=5.49 ;$ & Societal group: $\mu=4.1$ & $t_{(50)}=2.163 ;$ & $t_{(50)}=-1.880 ;$ \\
Rule breaking behavior & $S D=4.59$ & Clinical group: $\mu=6.7$ & $p<.05$ & $p<.10$ \\
& $M=1.62 ;$ & Societal group: $\mu=1.2$ & $t_{(50)}=1.811 ;$ & $t_{(50)}=-6.744 ;$ \\
Social problems & $S D=1.65$ & Clinical group: $\mu=3.2$ & $p<.10$ & $p<.001$ \\
& $M=3.55 ;$ & Societal group: $\mu=2.7$ & $t_{(50)}=2.053 ;$ & $t_{(50)}=-5.944 ;$ \\
Thought problems & $S D=2.95$ & Clinical group: $\mu=6.0$ & $p<.05$ & $p<.001$ \\
& $M=2.30 ;$ & Societal group: $\mu=0.9$ & $t_{(50)}=3.557 ;$ & $t_{(50)}=-3.557 ;$ \\
Attention problems & $S D=2.81$ & Clinical group: $\mu=3.7$ & $p<.01$ & $p<.01$ \\
& $M=4.65 ;$ & Societal group: $\mu=2.6$ & $t_{(50)}=3.196 ;$ & $t_{(50)}=-1.648 ;$ \\
& $S D=4.57$ & Clinical group: $\mu=5.7$ & $p<.01$ & $p=.11$
\end{tabular}

Means $(M)$ and standard deviations $(S D)$ are reported for the current sample. Comparison group values are provided as population means $(\mu)$

\section{Behavioral functioning, age at surgery, and type of craniosynostosis}

\section{Externalizing behaviors}

No statistically significant covariate effects or main effects of predictor variables were found for externalizing behaviors. However, the multivariate three-way interaction effect between age at first surgery, number of surgical operations, and craniosynostosis type was statistically significant $\left(F_{(4,}\right.$ 54) $=2.129 ; p<.10 ;$ partial $\left.\eta^{2}=.14\right)$. Tests of univariate effects indicate this effect to be statistically significant for aggressive behaviors $\left(F_{(2,27)}=2.653 ; p<.10\right.$; partial $\left.\eta^{2}=.16\right)$. The interaction is depicted in Fig. 1. As shown, for children with scaphocephaly, aggressive behaviors were more likely for those who had fewer operations at older ages; for both trigonocephaly and plagiocephaly, more surgical operations coupled with older age at first surgery were more likely to result in aggressive behavioral problems.

\section{Internalizing behaviors}

For covariate effects, the multivariate main effect of additional diagnoses was statistically significant $\left(F_{(3,25)}=7.975\right.$; $p<.01$; partial $\left.\eta^{2}=.49\right)$. Univariate analyses indicated this effect to be significant for somatic complaints $\left(F_{(1,27)}=\right.$ $10.966 ; p<.01$; partial $\eta^{2}=.29$ ). For predictor variables, the multivariate main effect of number of surgical operations on internalizing behaviors was statistically significant $\left(F_{(3,25)}=\right.$
3.455; $p<.05$; partial $\eta^{2}=.29$ ). Examination of the univariate model indicated this main effect to be statistically significant for somatic complaints $\left(F_{(1,27)}=23.973 ; p<.05\right.$; partial $\left.\eta^{2}=.19\right)$, such that more operations resulted in more somatic symptoms. However, this main effect was qualified by a statistically significant multivariate three-way interaction effect $\left(F_{(6,52)}=3.772 ; p<.01\right.$; partial $\left.\eta^{2}=.30\right)$, and specifically for the univariate effect on somatic complaints $\left(F_{(2,27)}=60.068\right.$; $p<.01$; partial $\left.\eta^{2}=.37\right)$. The interaction is depicted in Fig. 2 . As shown, for both children suffering from scaphocephaly and plagiocephaly, more surgical operations coupled with older ages at first surgery were more likely to result in somatic complaints; for children with trigonocephaly, more operations correlated with fewer somatic complaints, regardless of age at first surgery.

\section{Other $\mathrm{CBCL}$ scales}

No statistically significant results were found for analyses related to problems with thoughts and behaviors, attention problems, or social problems.

\section{DSM-oriented scales: internalizing disorders}

For covariate effects, the multivariate main effect of additional diagnoses was statistically significant $\left(F_{(3,25)}=11.532\right.$; $p<.001$; partial $\eta^{2}=.58$ ). Univariate analyses indicated this effect to be significant for somatic problems $\left(F_{(1,27)}=\right.$ 15.518; $p<.001$; partial $\left.\eta^{2}=.37\right)$. No statistically significant 
Table 2 Normed comparisons to the clinical populations on DSM variables

\begin{tabular}{lll}
\hline Variable & Descriptives & $t$ test results \\
\hline Anxiety problems & $M=2.50 ; S D=1.91 ; \mu=3.6$ & $t_{(50)}=-6.855 ; p<.001$ \\
Depressive problems & $M=2.99 ; S D=2.52 ; \mu=5.4$ & $t_{(50)}=-4.091 ; p<.001$ \\
Somatic problems & $M=1.66 ; S D=2.82 ; \mu=1.4$ & $t_{(50)}=.651 ; p=.52$ \\
Oppositional defiant problems & $M=1.95 ; S D=1.66 ; \mu=3.9$ & $t_{(50)}=-8.406 ; p<.001$ \\
Conduct problems & $M=1.45 ; S D=2.34 ; \mu=4.1$ & $t_{(50)}=-8.089 ; p<.001$ \\
Sluggish cognitive tempo & $M=1.25 ; S D=1.24 ; \mu=1.8$ & $t_{(50)}=-3.179 ; p<.01$ \\
ADHD & $M=3.90 ; S D=3.65 ; \mu=4.8$ & $t_{(50)}=-1.762 ; p=.08$ \\
OCD & $M=2.35 ; S D=2.38 ; \mu=4.1$ & $t_{(50)}=-.44 ; p=.66$ \\
PTSD & $M=5.26 ; S D=3.48 ; \mu=4.7$ & $t_{(50)}=1.153 ; p=.25$ \\
\hline
\end{tabular}

Means $(M)$ and standard deviations $(S D)$ are reported for the current sample. Comparison group values are provided as population means $(\mu)$ main effects of the predictor variables were found. However, the multivariate three-way interaction effect between age at first surgery, number of surgical operations, and craniosynostosis type was statistically significant $\left(F_{(6,52)}=1.990 ; p<.10\right.$; partial $\left.\eta^{2}=.18\right)$. Tests of univariate effects indicate this effect to be statistically significant for somatic problems $\left(F_{(2,27)}=\right.$ 26.214; $p<.05 ;$ partial $\eta^{2}=.28$ ). The interaction is depicted in Fig. 3. As shown, for both children with scaphocephaly and plagiocephaly, more surgical operations coupled with older ages at first surgery were more likely to result in somatic problems. For children with trigonocephaly, more operations at older ages resulted in a lower likelihood of somatic problems.

\section{Other DSM-oriented scales}

No statistically significant results were found for analyses related to externalizing disorders, PTSD, OCD, or ADHD.

\section{Exploratory analyses}

Because both sex and age of the child have been found to coincide with childhood behavioral disorders, the effects of child age and child sex were regressed on each of the three behavioral disorder variables in Figs. 1, 2, and 3 (aggressive behaviors, somatic complaints, and somatic problems). Neither the main nor joint effects of either child age nor child sex significantly predicted any of these variables, thus eliminating these demographic factors as potential alternative explanations for the currently found results.

\section{Discussion}

This study examined behavioral adjustment in school-aged children treated for single suture craniosynostosis and included evaluation of the interactive effects of the age at which children underwent their first surgical procedure, the number of surgical operations, and the specific type of suture involved. Results indicate that overall, school-aged children with single suture craniosynostosis have higher scores on the CBCL than the general population; specific elevations were observed including somatic complaints, aggressive behavior, social problems, attention problems, and thought problems and rulebreaking behavior. The scores of our sample were in significantly lower than the clinical norm group in all but two scales: somatic complaints and aggressive behavior.

We also observed that behavioral functioning varied by number of surgical procedures, type of craniosynostosis, and age at first surgery. Increasing numbers of surgical operations and an older age in first surgery were associated with more somatic complaints: for children with scaphocephaly and plagiocephaly. Aggressive behaviors were more likely for those who had fewer operations at older ages; for both trigonocephaly and plagiocephaly, more surgical operations coupled with older age at first surgery were more likely to result in aggressive behavioral problems.

For both children with scaphocephaly and plagiocephaly, more surgical operations coupled with older ages at first surgery more likely to result in more somatic problems; for
Table 3 Cronbach alphas of CBCL subscales

\begin{tabular}{ll}
\hline CBCL subscales & Alphas \\
\hline Anxious/depressed & 0.68 \\
Withdrawn/depressed & 0.65 \\
Somatic complaints & 0.77 \\
Social problems & 0.71 \\
Thought problems & 0.73 \\
Attention problems & 0.89 \\
Rule breaking behavior & 0.43 \\
Aggressive behavior & 0.85 \\
PTSD & 0.66 \\
OCD & 0.69 \\
Slow cognitive tempo & 0.44 \\
Somatic problems & 0.81 \\
\hline
\end{tabular}


Fig. 1 Three-way interactive effect of age of first surgery, number of surgeries, and craniosynostosis type on aggressive behaviors
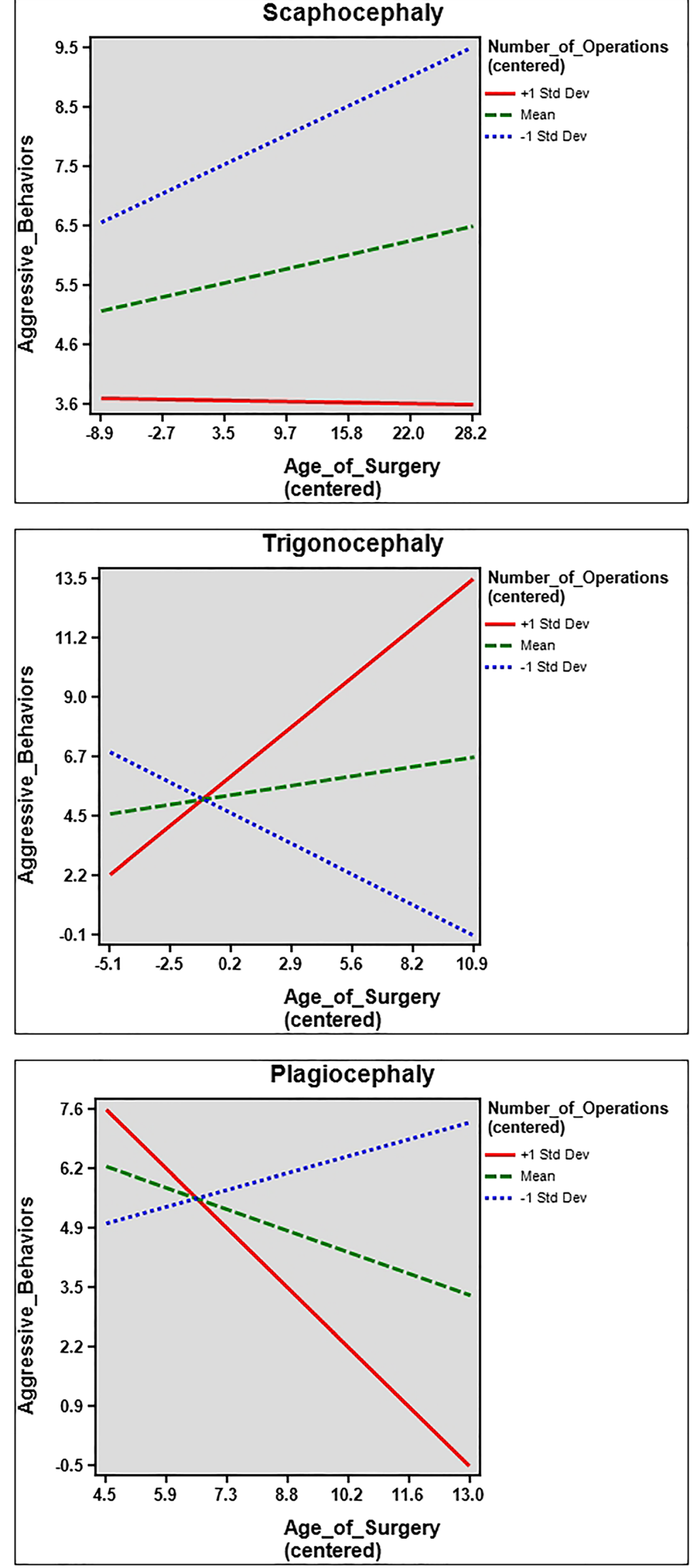
Fig. 2 Three-way interactive effect of age of first surgery, number of surgeries, and craniosynostosis type on somatic pains
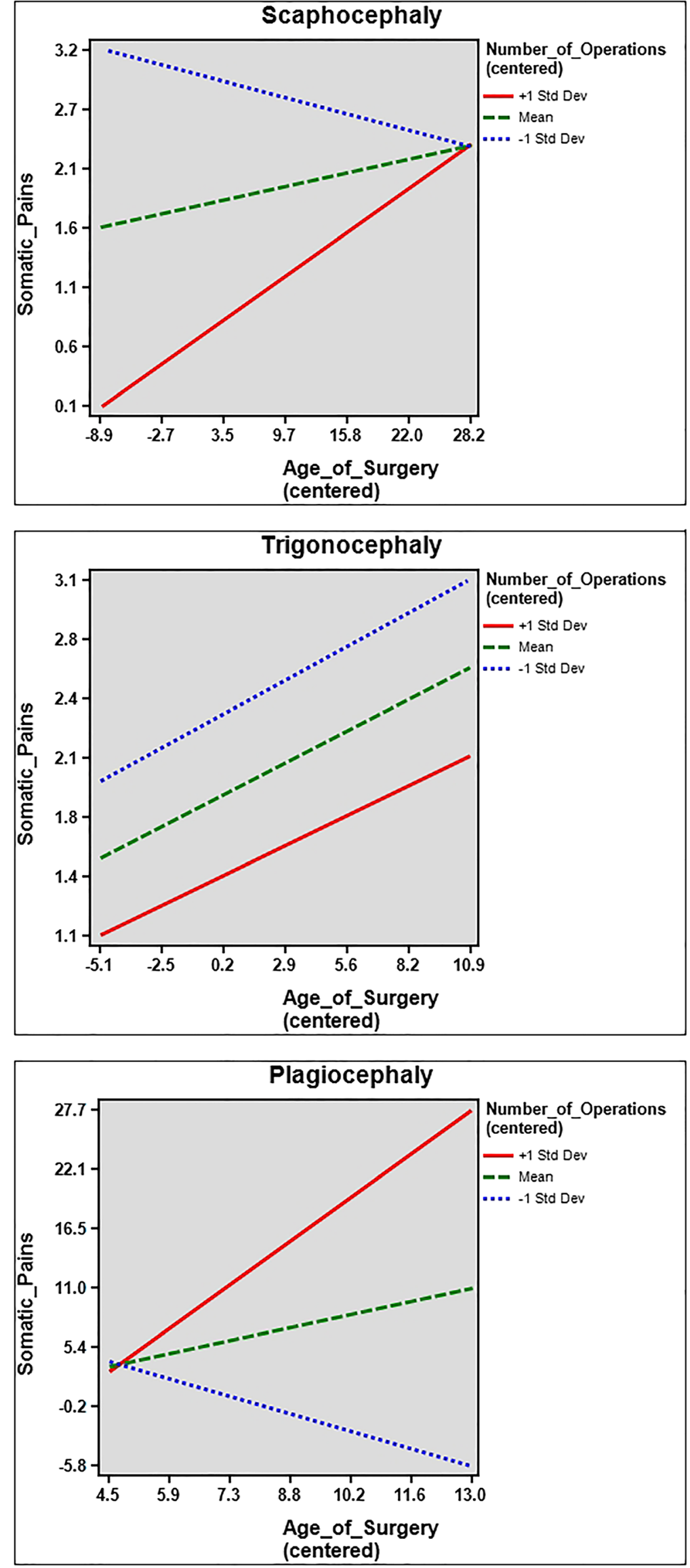
Fig. 3 Three-way interactive effect of age of first surgery,

number of surgeries, and

craniosynostosis type on

somatization disorders
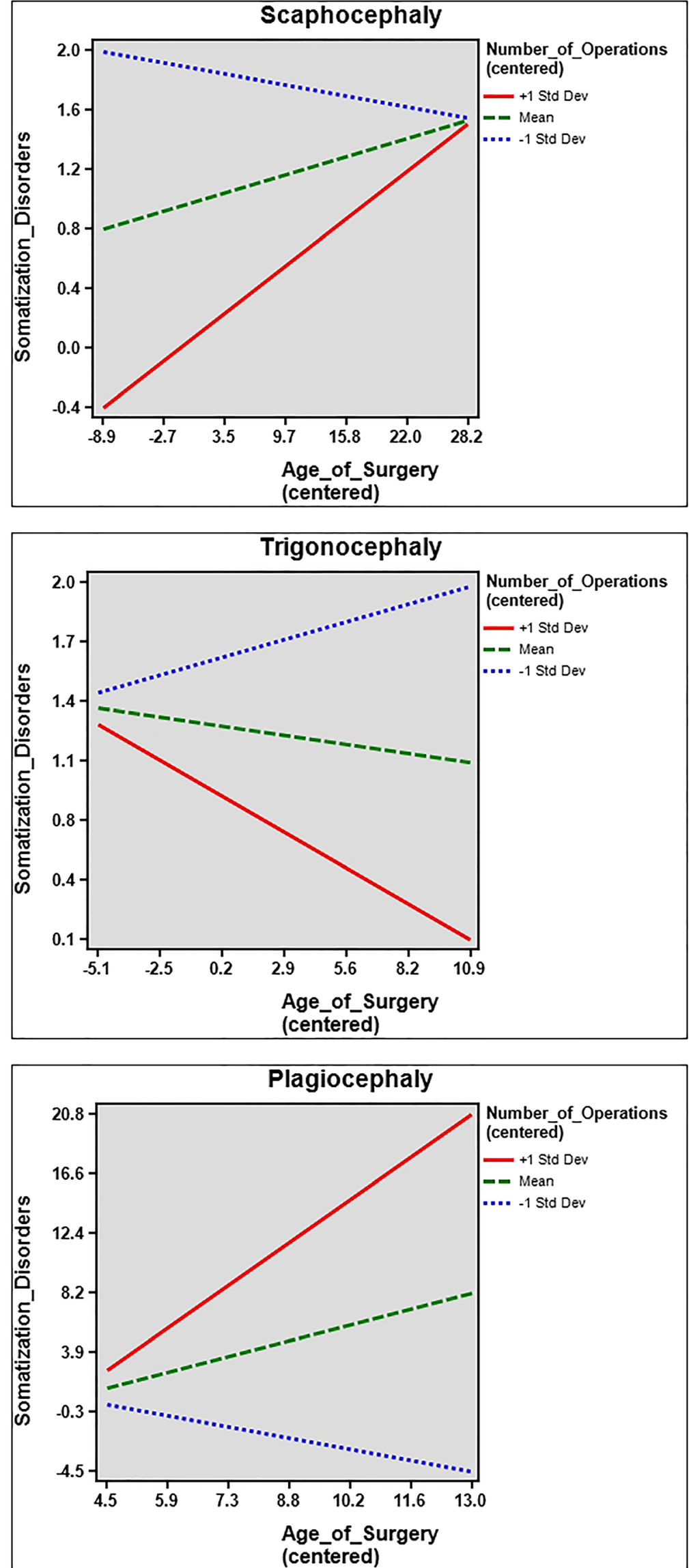
children with trigonocephaly, more operations at older ages resulted in less somatic problems.

Our results are consistent with other reports in the literature in that children with craniosynostosis had CBCL significantly higher scores compared to controls or the norm group $[12,14]$. Researchers also find scores increasing with age $[13,15]$. Speltz et al. (2016) found that children's scores reach above the clinical threshold in social problems, thought problems, aggressive behavior, and rule breaking behavior whereas in our sample, we have observed clinical range scores in somatic complaints and attention problems. Since researchers consistently report elevated CBCL scores for children with craniosynostosis, psychosocial screening, particularly during school age, should be strongly encouraged.

Even though researchers also investigated diagnosisspecific patterns among cases and found behavior problems to be more common for children with metopic synostosis and lowest among those with sagittal synostosis, most observed limited evidence for unique behavior problems associated with specific types of craniosynostosis $[15,26]$. However, our findings indicate diagnosis-specific patterns especially impacted by the first age of the surgery and number of surgeries. Similar to our findings, Chiefo et al. (2010) reported diagnostic specific patterns with regards to attention, visual memory, processing, and speech impacting children with sagittal and unicoronal craniosynostosis. The authors stated that particularly attention deficits would contribute the behavioral changes in children with sagittal craniosynostosis.

Our study has several limitations, including a modest response rate, relatively small sample size, lack of a control group, and additional evaluations for cognitive functioning. Our findings are further limited by reliance on parent reports of behavioral functioning, which could be biased by their knowledge of the child and his/her history. It is also possible that families of children with behavioral concerns were more likely to take part in this study given the topic. Other researchers have recommended inclusion of teacher observations as they may yield less biased reports of child behavior [14]. Clinically, obtaining teacher observations could also be helpful in screening for behavioral and other cognitive risks in this population. Larger, longitudinal studies with control groups are indicated to better understand behavioral risks in children with single suture craniosynostosis.

Despite these limitations, our results do support the need for ongoing surveillance for behavior problems, primarily for aggressive behavior, somatic complaints, and somatic problems in children with single suture craniosynostosis during childhood and adolescence and referral for appropriate psychological interventions as indicated. Thus, increased intracranial pressure and cosmetic concerns do not seem to be the only areas of concerns for craniosynostosis patients; multidisciplinary teams suitable to conduct assessments of behavioral problems are necessary.

\section{Compliance with ethical standards}

Conflict of interest On behalf of all authors, the corresponding author states that there is no conflict of interest.

\section{References}

1. Speltz ML, Kapp-Simon KA, Cunningham M, Marsh J, Dawson G (2004) Single-suture craniosynostosis: a review of neurobehavioral research and theory. J Pediatr Psychol 29(8):651-668. https://doi. org/10.1093/jpepsy/jsh068

2. Da Costa AC (2004) Neuropsychological profiles of children and adolescents with craniosynostosis. Doctor of Psychology Thesis, Victoria University of Technology, Melbourne, Australia. http:// vuir.vu.edu.au/15342/

3. Bottero L, Lajeunie E, Arnaud E, Marchac D, Renier D (1998) Functional outcome after surgery for trigonocephaly. Plast Reconstr Surg 102:952-958. https://doi.org/10.1097/00006534199809040-00002

4. Da Costa AC, Anderson VA, Savarirayan R, Wrennall JA, Chong DK, Holmes AD, Greensmith AL, Meara JG (2012) Neurodevelopmental functioning of infants with untreated singlesuture craniosynostosis during early infancy. Childs Nerv Syst 28: 869-877. https://doi.org/10.1007/s00381-011-1660-1

5. Ozgur B, Aryan HE, Ibrahim D, Soliman MA, Meltzer HS, Cohen SR, Levy ML (2006) Emotional and psychological impact of delayed craniosynostosis repair. Childs Nerv Syst 22:1619-1623. https://doi.org/10.1007/s00381-006-0148-x

6. Bellew M, Liddington M, Chumas P, Russell J (2011) Preoperative and postoperative developmental attainment in patients with sagittal synostosis: 5-year follow-up. J Neurosurg Pediatr 7:121-126. https://doi.org/10.3171/2010.11.PEDS10216

7. Shipster C, Hearst D, Somerville A, Stackhouse J, Hayward R, Wade A (2003) Speech, language and cognitive development in children with isolated sagittal craniosynostosis. Dev Med Child Neurol 45:34-43. https://doi.org/10.1017/S0012162203000070

8. Starr J, Collett B, Gaither R, Kapp-Simon K, Cradock M, Cunningham M, Speltz M (2012) Multi-center study of neurodevelopment in 3-year-old children with or without singlesuture craniosynostosis. Arch Pediatric Adolesc Med 166:536542. https://doi.org/10.1001/archpediatrics.2011.1800

9. Foster KA, Frim DM, McKinnon M (2008) Recurrence of synostosis following surgical repair of craniosynostosis. Plast Reconstr Surg 121(3):70e-76e. https://doi.org/10.1097/01.prs.0000299393. 36063.de

10. Da Costa AC, Anderson VA, Holmes AD, Lo P, Wray AC, Chong DK, Greensmith AL, Meara JG (2013) Longitudinal study of the neurodevelopmental characteristics of treated and untreated nonsyndromic craniosynostosis in infancy. Childs Nerv Syst 29:985995. https://doi.org/10.1007/s00381-012-2017-0

11. Magge S, Westerveld M, Pruzinsky T, Persing J (2002) Long-term neuropsychological effects of sagittal craniosynostosis on child development. J Craniofac Surg 13:99-104. https://doi.org/10.1097/ 00001665-200201000-00023

12. Becker DB, Petersen JD, Kane AA, Cradock MM, Pilgram TK, Marsh JL (2005) Speech, cognitive, and behavioral outcomes in nonsyndromic craniosynostosis. Plast Reconstr Surg 116:400407. https://doi.org/10.1097/01.prs.0000172763.71043.b8

13. Cloonan YK, Collett B, Speltz ML, Anderka M, Werler MM (2013) Psychosocial outcomes in children with and without nonsyndromic craniosynostosis: findings from two studies. Cleft Palate-Cran J 50:406-413. https://doi.org/10.1597/11-074 
14. Speltz ML, Collett BR, Wallace ER, Kapp-Simon K (2016) Behavioral adjustment of school-age children with and without single-suture craniosynostosis. Plast Reconstr Surg 138:435-445. https://doi.org/10.1097/PRS.0000000000002383

15. Kapp-Simon KA, Collett BR, Barr-Schinzel MA, Cradock MM, Buono LA, Pietila KE, Speltz ML (2012) Behavioral adjustment of toddler and preschool-aged children with single-suture craniosynostosis. Plast Reconstr Surg 130:635-647. https://doi.org/10. 1097/PRS.0b013e31825dc18b

16. Cradock MM, Gray KE, Kapp-Simo KA, Collett BR, Buono LA, Speltz ML (2015) Sex differences in the neurodevelopment of school-age children with and without single-suture craniosynostosis. Childs Nerv Syst 31:1103-1111. https://doi.org/10.1007/ s00381-015-2671-0

17. Millichap JG (2015) Cognitive development of children with craniosynostosis. Pediatr Neurol Briefs 29:47-47. https://doi.org/10. 15844/pedneurbriefs-29-6-6

18. Aslan C, Olgun ZD, Ertas ES, Ozusta S, Demirkiran G, Unal F, Yazici M (2017) Psychological profile of children who require repetitive surgical procedures for early onset scoliosis: is a poorer quality of life the cost of a straighter spine? Spine Deformity 5: 334-341. https://doi.org/10.1016/j.jspd.2017.03.007

19. Achenbach TM, Rescorla LA (2001) Manual for ASEBA schoolage forms \& profiles. University of Research Center for Children, Youth \& Families, Burlington

20. Erol N, Simsek Z, Munir K (2009) Mental health of adolescents reared in institutional care in Turkey: challenges and hope in the twenty-first century. Eur Child Adoles Psy 19:113-124. https://doi. org/10.1007/s00787-009-0047-2

21. Erol N, Șimșek Z (2010) Okul Çağı Çocuk ve Gençler için Davranış Değerlendirme Ölçekleri El Kitabı (CBCL, YSR ve TRF). Mentis, Ankara

22. DeSimone JA, Harms PD (2017) Dirty data: the effects of screening respondents who provide low-quality data in survey research. J Bus Psychol 33:559-577. https://doi.org/10.1007/s10869-017-9514-9

23. Graham JW, Cumsille PE, Elek-Fisk E (2003) Methods for handling missing data. In: Schinka JA, Velicer WF (eds) Handbook of psychology: research methods in psychology $2: 87-114$. Wiley, Hoboken

24. Liakhovitski D, Stone-Romero EF, Jaccard JJ (2008) Strategies for detecting joint dichotomous moderators in human resource management research. Hum Resour Manag Rev 18:164-179. https:// doi.org/10.1016/j.hrmr.2008.07.005

25. Soper DS (2015) Interaction (Software Program), http://www. danielsoper.com.

26. Collett BR, Kapp-Simon KA, Wallace E, Cradock MM, Buono L, Speltz ML (2017) Attention and executive function in children with and without single-suture craniosynostosis. Child Neuropsychology 23:83-98. https://doi.org/10.1080/09297049. 2015.1085005

Publisher's note Springer Nature remains neutral with regard to jurisdictional claims in published maps and institutional affiliations. 